\title{
Characteristics of atmospheric Total Gaseous Mercury (TGM) observed in urban Nanjing, China
}

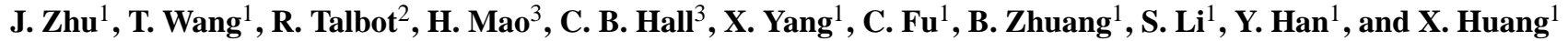 \\ ${ }^{1}$ School of Atmospheric Sciences, Nanjing University, Nanjing 210093, China \\ ${ }^{2}$ Department of Earth \& Atmospheric Sciences, University of Houston, Houston, TX 77204, USA \\ ${ }^{3}$ Department of Chemistry, State University of New York, College of Environmental Science and Forestry, Syracuse, NY \\ 13219, USA
}

Correspondence to: T. Wang (tjwang@nju.edu.cn)

Received: 10 August 2012 - Published in Atmos. Chem. Phys. Discuss.: 21 September 2012

Revised: 5 December 2012 - Accepted: 14 December 2012 - Published: 20 December 2012

\begin{abstract}
Long-term continuous measurements of total gaseous mercury (TGM=gaseous elemental mercury (GEM) + reactive gaseous mercury (RGM)) were conducted simultaneously along with meteorological variables and a suite of trace gases at an urban site in Nanjing, China from 18 January to 31 December 2011. Measurements were conducted using a high resolution mercury vapor analyzer (Tekran 2537B) with 5-min time resolution. The average concentration of TGM was $7.9 \pm 7.0 \mathrm{ng} \mathrm{m}^{-3}$ with a range of $0.8-$ $180 \mathrm{ng} \mathrm{m}^{-3}$ over the study period. TGM concentrations followed a typical lognormal pattern dominated by a range of 3$7 \mathrm{ng} \mathrm{m}^{-3}$, which was significantly higher than the continental background values $\left(\sim 1.5 \mathrm{ng} \mathrm{m}^{-3}\right)$ in Northern Hemisphere. The mean seasonal TGM concentrations decreased in the following order: summer, spring, fall, and winter. This seasonal pattern was quite different from measurements at most other sites around the world. We attributed high monthly average concentrations to the re-volatilization of deposited mercury during the warm season due to high temperatures and greater solar radiation. Previous modeling studies suggested that Nanjing and the surrounding region have the largest Chinese natural emissions during the summer. Positive correlations between temperature, solar radiation, and TGM concentration combined with no correlation between CO and TGM in summer provide a strong indication that natural sources are important in Nanjing while most sharp peaks were caused by anthropogenic sources. TGM concentrations in Nanjing exhibited a noticeable diurnal pattern with a sharp increase after sunrise and peak of greater than $8 \mathrm{ng} \mathrm{m}^{-3}$ during 710 a.m. local time. Further, seasonally averaged diurnal cy-
\end{abstract}

cles of TGM exhibited considerably different patterns with the largest variation in spring and insignificant fluctuations in winter. Using HYSPLIT backwards trajectories from six clusters, it was indicated that the highest TGM concentrations, $11.9 \mathrm{ng} \mathrm{m}^{-3}$, was derived from local air masses. The cleanest air masses, with an average TGM concentration of 4.7 and $5.9 \mathrm{ng} \mathrm{m}^{-3}$, were advected from the north via fast transport facilitated by sweeping synoptic flows.

\section{Introduction}

Mercury ( $\mathrm{Hg}$ ) is a pervasive toxic pollutant and poses serious harm to human health via bioaccumulation of methylated mercury through the food chain in aquatic systems (Schroeder and Munthe, 1998; Lindqvist, 1991). The atmosphere is a major route for the transport and transformation of mercury from sources to receptors (Mason et al., 1994; Fitzgerald et al., 1998). In the atmosphere, mercury typically exists in three forms: gaseous elemental mercury (GEM), reactive gaseous species (RGM) and particulate mercury $\left(\mathrm{Hg}^{P}\right)$. Unlike other heavy metals, which tend to exist only in the particulate phase, mercury exists mainly as GEM (>95\%)(Slemr et al., 1985; Schroeder and Munthe, 1998; Poissant et al., 2005; Gabriel et al., 2005; Aspmo et al., 2006; Valente et al., 2007) and can be transported far beyond the regions where it is emitted due to its high volatility, low chemical reactivity and low solubility in water; therefore it is well-mixed hemispherically (Slemr et al., 1985). The lifetime of GEM on the hemispheric scale is $\sim 0.5-2 \mathrm{yr}$, whereas 
RGM and $\mathrm{Hg}^{P}$ are more soluble and thus quickly scavenged via wet and dry deposition (Schroeder and Munthe, 1998). GEM can be oxidized to RGM, a portion of RGM is further transformed to $\mathrm{Hg}^{P}$ on aerosol surfaces.

Both natural processes and anthropogenic activities release mercury to the atmosphere. Natural sources include evasion from soil surface, water bodies, vegetation surfaces, wild fires, volcanoes, and geothermal sources (Schroeder and Munthe, 1998). The annual global mercury emissions attributable to anthropogenic activities are approximately 2000 tons per year (Pacyna et al., 2006). Anthropogenic mercury emissions in Asia are the highest in the world, accounting for about $54 \%$ of the global total (Pacyna et al., 2010). China is considered as a large and growing source region because of its rapid economic and industrial growth along with a coaldominated energy structure (Wu et al., 2006). The Yangtze River Delta (YRD), central China and Guizhou province are major anthropogenic source regions in China (Street et al., 2005). Thus quantifying mercury levels in these regions is imperative.

Monitoring the variation of ambient mercury concentrations in the atmosphere enables us to understand the fate of mercury. Mercury measurements have been made at numerous locations worldwide. Sprovieri et al. (2010, references therein) reviewed a large suite of measurement studies and summarized that the background concentration of atmospheric total gaseous mercury $(\mathrm{TGM}=\mathrm{GEM}+\mathrm{RGM})$ in the Northern Hemisphere ranges from 1.5 to $1.7 \mathrm{ng} \mathrm{m}^{-3}$. Slemr et al. (2003) showed that atmospheric mercury concentrations increased in the late 1970 s to a peak in the 1980s followed by a decreasing trend since then. In contrast, Wu et al. (2006) found increasing anthropogenic emissions in China at an average of $2.9 \%$ per year during the period 1995-2000, and the pollution problem has become even more serious in recent years. However, research on atmospheric mercury in China is limited. Most measurements were conducted in southwestern China. Specifically, Feng et al. (2004), Liu et al. (2011), and Zheng et al. (2007) found mean TGM concentrations in Guiyang ranged from 6.4 to $9.1 \mathrm{ng} \mathrm{m}^{-3}$. Short-term measurements made in urban areas such as Beijing (Liu et al., 2002) and Changchun (Fang et al., 2004) as well as in remote regions such as Mt. Changbai (Wan et al., 2009) and Mt. Gongga (Fu et al., 2008a, b) suggested that TGM concentrations were elevated above the Northern Hemispheric background level.

The Yangtze River Delta (YRD) region is situated in eastern China including part of Zhejiang and Jiangsu Provinces and the Shanghai Municipality. It is known as one of the most industrialized and urbanized regions in China. Due to the rapid development and a high population density in the YRD region, environmental pollution has become a problem of increasing concern. However, atmospheric mercury was largely ignored in previous studies of pollution in YRD, and thus the extent of mercury contamination in the region is still unknown. To the best of our knowledge, few comprehensive measurements and analysis campaigns concerning TGM and other trace gases have been performed in China. In this paper, we report for the first time long-term continuous measurements of TGM together with their linkage to meteorological conditions and other trace gases in the YRD urban region during 2011.

\section{Experimental methodology}

\subsection{Study area and sampling site}

Nanjing, the capital of Jiangsu province, is located in the northwest of the YRD region and west of the East China Sea (Fig 1). It is the second largest city in eastern China with a high population density and large energy consumption. The climate is a typical humid subtropical type with an average annual temperature of $15.5^{\circ}$ and average annual precipitation of $1019.5 \mathrm{~mm}$ (Meteorological Bureau of Jiangsu Province). The prevailing wind direction is southeasterly from the $\mathrm{Pa}$ cific Ocean in summer and northwest from inland China in winter. Industry is the dominant economic pillar of Nanjing. Local industries include steel mills, coal fired power plants, and several large non-ferrous smelters. In addition, there are over one million vehicles in Nanjing currently, and that number is increasing steadily.

Our site $\left(32.05^{\circ} \mathrm{N}, 118.78^{\circ} \mathrm{E}\right)$ is centrally located in the main urban area of Nanjing. Data was collected from the top of a 24 story building on the Gulou campus of Nanjing University (NJU). The sampling height is about $79 \mathrm{~m}$ above the street and the sample inlet was about $2 \mathrm{~m}$ above the floor of site. There are no large industrial pollution sources within a $30 \mathrm{~km}$ radius, but several main roads with apparent traffic pollution surround the campus.

\subsection{Measurements}

\subsubsection{Sampling of TGM}

Real time continuous measurements of TGM were made during the time period of 18 January-31 December 2011 using an automated mercury vapor analyzer Tekran 2537B. The sampled air was measured with a 5 minutes time resolution at a flow rate of $1.5 \mathrm{~L} \mathrm{~min}^{-1}$ and measured using cold vapor atomic fluorescence spectroscopy (CVAFS). Detailed information about this instrument can be found in Mao et al. (2008).

The Tekran 2537B performed automated recalibrations every 24 hours using an internal permeation source (Xia et al., 2010). The TGM detection limit is $<0.1 \mathrm{ng} \mathrm{m}^{-3}$. The accuracy of the GEM measurements is $\pm 5 \%$ due to periodic maintenance and attention to instrument operation (Mao et al., 2008). Zero air was used to blank to the instrument. Air stream was collected through PFA Teflon tube which was tested with result of about $100 \%$ RGM passing efficiency. Even if there is very little RGM $(<2 \%)$ being removed 


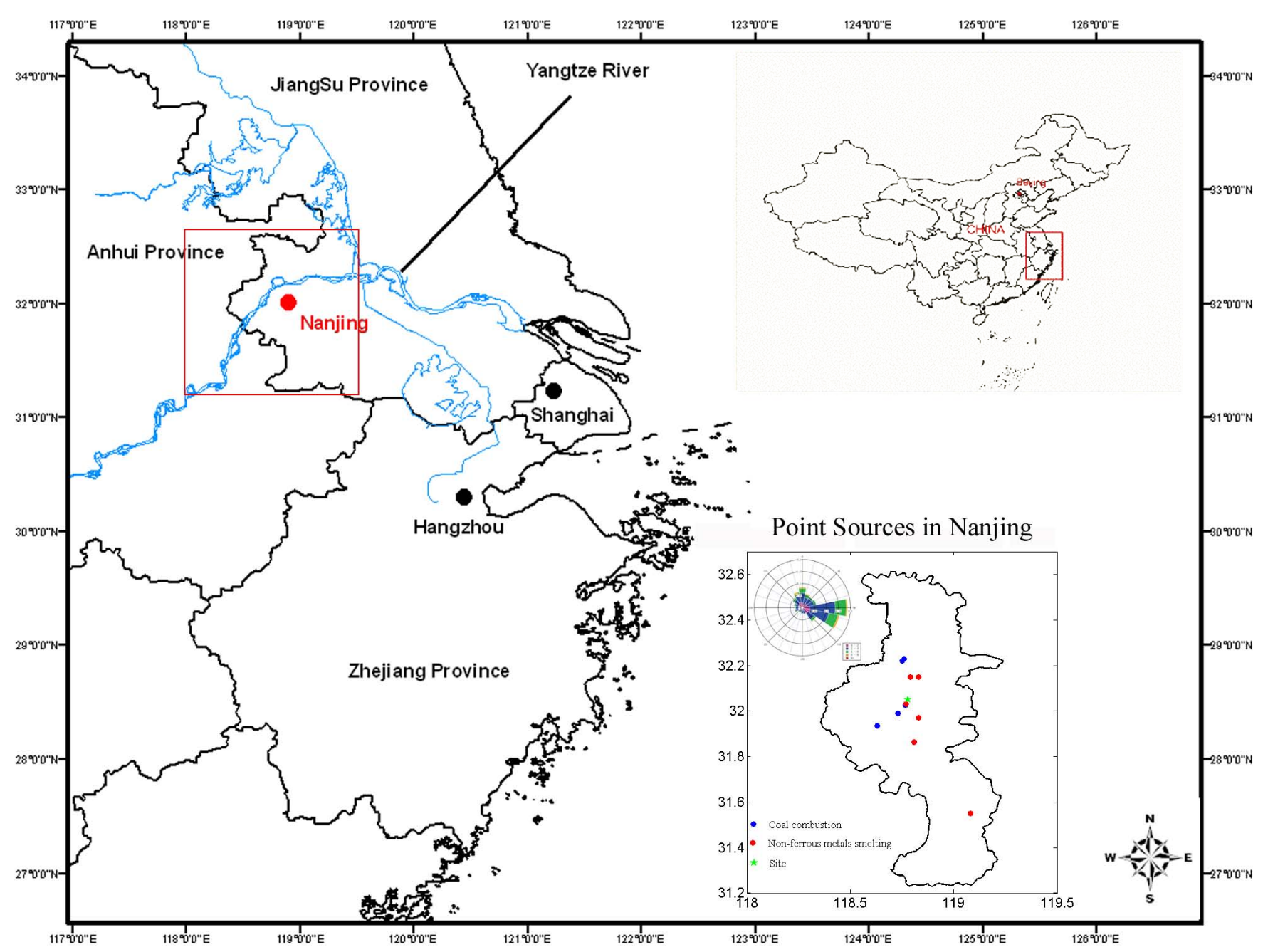

Fig. 1. The location of our site and important point sources in Nanjing.

occasionally during sample period due to kinds of different conditions, it hardly influences our analysis of TGM characteristic. Some periods in which we were unable to retrieve data due to electricity shortages or lack of carrier gas include the following days: (1) 8-11 April; (2) 1-3 May; (3) 23 May9 June; (4) 27 June-1 July; (5) 31 July-1 August. Except for these periods and some short maintenance periods, we collected nearly one year of continuous measurements. The date was recorded in local time $(\mathrm{GMT}+8)$.

\subsubsection{Meteorological parameters and other chemical compounds}

Meteorological parameters including temperature, air pressure, and relative humidity were measured simultaneously with TGM at the same site every minute. Wind direction and wind speed were provided by the National Meteorological Station of Nanjing (ID 58238, 31.9 ${ }^{\circ} \mathrm{N}, 118.9^{\circ} \mathrm{E}$ ). Solar radiation was measured in Nanjing at the Caochangmen environmental monitoring station, which is several kilometers away from our site. The wind and solar radiation data had a onehour time resolution. In addition, we concurrently collected trace gases including $\mathrm{CO}$ and $\mathrm{O}_{3}$ at our site with a one-minute time resolution. $\mathrm{CO}$ was measured using a Thermo Model 48i-TLE CO Analyzer and a Thermo Model 49i O 3 Analyzer measured $\mathrm{O}_{3}$. The instruments were operated in a manner identical to that described by Mao and Talbot (2004).These gases were measured from 18 January to 31 May except CO which ended on 31 December 2011. In order to have data comparable to TGM, we generated five-minute averages from the one-minute data collected.

\section{Results and discussions}

\subsection{General characteristics of TGM}

Figure 2 shows the time series of 5-min averaged TGM concentrations in ambient air at our sampling site for the entire study period (18 January-31 December 2011). The 


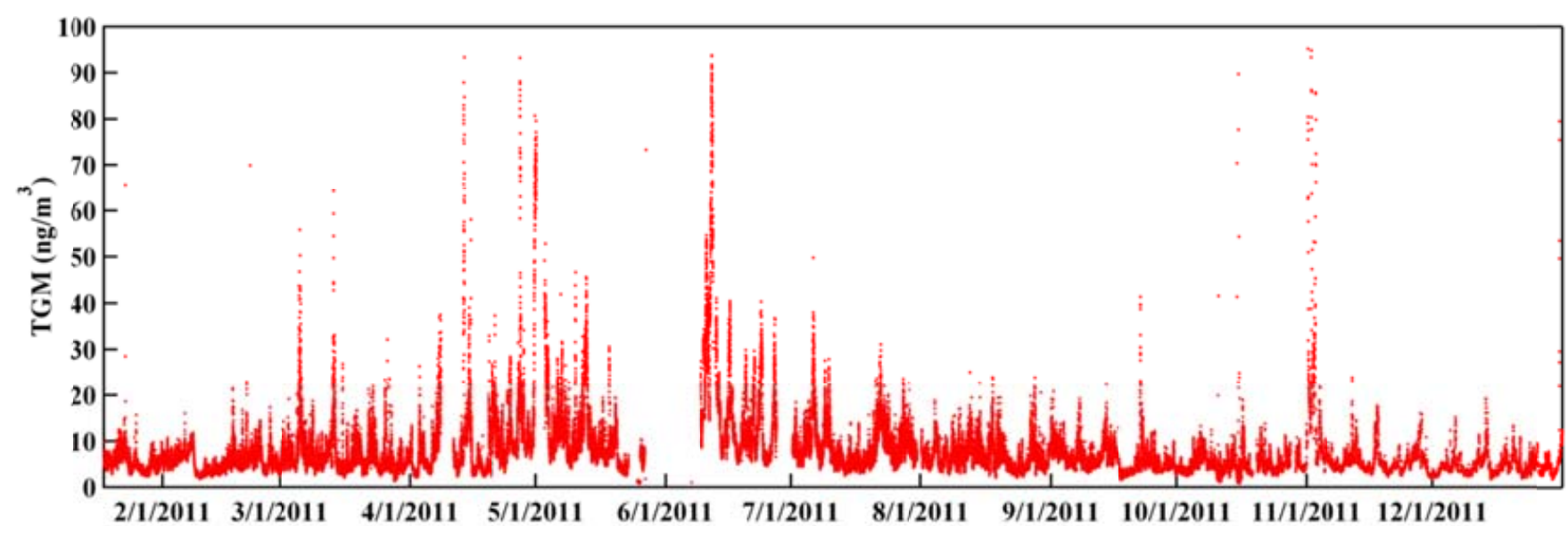

Fig. 2. Time series of $5 \mathrm{~min}$ averaged TGM concentrations in Nanjing.

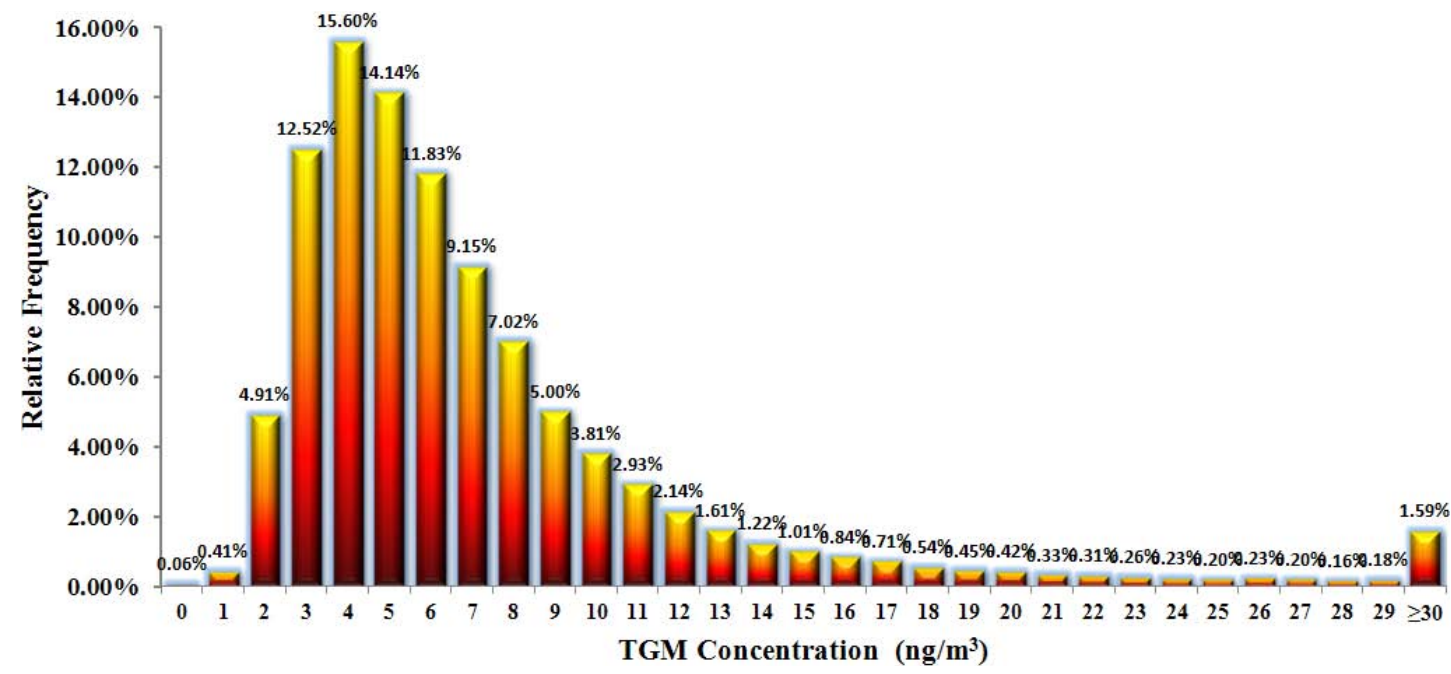

Fig. 3. Frequency distribution of TGM for the whole campaign period.

distribution of TGM was characterized by large variability throughout the sampling period. The mean concentration for TGM was $7.9 \pm 7.0 \mathrm{ng} \mathrm{m}^{-3}$ with a range of $0.8-180 \mathrm{ng} \mathrm{m}^{-3}$. We also noticed that the median value of $6.2 \mathrm{ng} \mathrm{m}^{-3}$ was much less than the average. This indicates that there were some extreme pollution episodes with very high TGM. All statistical results for the data collected over the whole measurement period by season are summarized in Table 1 .

The mean concentration of TGM was a factor of $\sim 5$ higher than the Northern Hemisphere background level of $\sim 1.5 \mathrm{ng} \mathrm{m}^{-3}$. To put our measurements into perspective, a compilation of world-wide short and long-term TGM measurements is presented in Table 2. Overall, TGM concentrations at urban and suburban sites are higher than those at rural sites. TGM levels in Nanjing are comparable to the average concentration of other Chinese urban sites. However, measurements from Shanghai and Ningbo urban sites, which are also situated in the same region (YRD) with Nanjing, showed less than half of the mean concentration from our site. One reason might the short duration of those studies. Moreover, the coastal positions of Shanghai and Ningbo may reduce contamination episodically by diluting with cleaner marine air and GEM reacting with oceanic bromine. Compared with TGM measurements in other countries (Table 2), the level in Nanjing is similar to some other developing countries (such as Mexico) and East Asian countries (such as Korea and Japan). However, TGM measurements in North America and Europe generally showed lower average and maximum levels.

The frequency distribution of the high-resolution TGM data from our measurement campaign is shown in Fig. 3. TGM concentrations followed a typical lognormal pattern. The range 3 to $7 \mathrm{ng} \mathrm{m}^{-3}$ dominated the distribution, accounting for more than half of the total data samples. The maximum frequency of $15.6 \%$ occurred between 4 and $5 \mathrm{ng} \mathrm{m}^{-3}$. Episodes with extremely high TGM concentrations were also 
Table 1. The statistical summary of 5-min average TGM data $\left(\mathrm{ng} \mathrm{m}^{-3}\right)$.

\begin{tabular}{llllll}
\hline & Range & Mean & Median & SD & N \\
\hline Spring & $0.9 \sim 179.8$ & 9.2 & 7.3 & 8.0 & 22232 \\
Summer & $1.0 \sim 93.8$ & 9.9 & 7.5 & 8.2 & 21724 \\
Fall & $0.8 \sim 149.1$ & 6.0 & 5.1 & 5.2 & 17868 \\
Winter & $1.8 \sim 79.5$ & 5.5 & 5.1 & 2.5 & 14327 \\
All-data & $0.8 \sim 179.8$ & 7.9 & 6.2 & 7.0 & 76151 \\
\hline
\end{tabular}

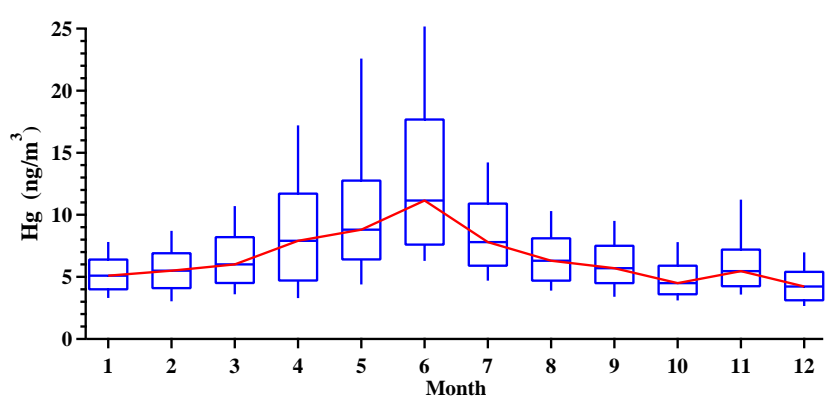

Fig. 4. Monthly variation of TGM concentration with 10th, 25th, median, 75th and 90th percentile values.

apparent, but they comprised a small portion of the TGM data sets with $4.1 \%$ exceeding $20 \mathrm{ng} \mathrm{m}^{-3}$.

\subsection{Seasonal variation}

\subsubsection{Overall description}

The TGM concentrations in Nanjing showed distinct seasonality during the study period. Figure 4 shows the monthly variation of TGM concentration with 10th, 25th, median, 75 th and 90th percentile values for each month. The monthly median value increased steadily from January and peaked in June at $11.2 \mathrm{ng} \mathrm{m}^{-3}$ followed by a decline reaching a minimum in December at $4.2 \mathrm{ng} \mathrm{m}^{-3}$.The December median was only $\sim 38 \%$ of the level observed in June. The difference between 25 th and 75 th percentile was $10.1 \mathrm{ng} \mathrm{m}^{-3}$ in June compared to $<3 \mathrm{ng} \mathrm{m}^{-3}$ in the winter season (January, February and December). However, the difference between the 10th and 25 th percentiles was modest in all months.

The seasonal characteristics of TGM are summarized in Table 1. The seasonal mean concentration decreased in the order: summer, spring, fall, to winter. The difference in the mean value between summer and winter was $4.4 \mathrm{ng} \mathrm{m}^{-3}$, which corresponds to approximately $56 \%$ of the annual mean TGM concentration of $7.9 \mathrm{ng} \mathrm{m}^{-3}$. The largest range $0.9-179.8 \mathrm{ng} \mathrm{m}^{-3}$ was observed in spring and the smallest $1.8-79.5 \mathrm{ng} \mathrm{m}^{-3}$ in winter. The standard deviations in the four seasons were positively correlated with mean and median values. The data for each season was divided into five subsets to indicate the frequency of different TGM levels during the four seasons (Fig. 5). The episodes of the highest con-

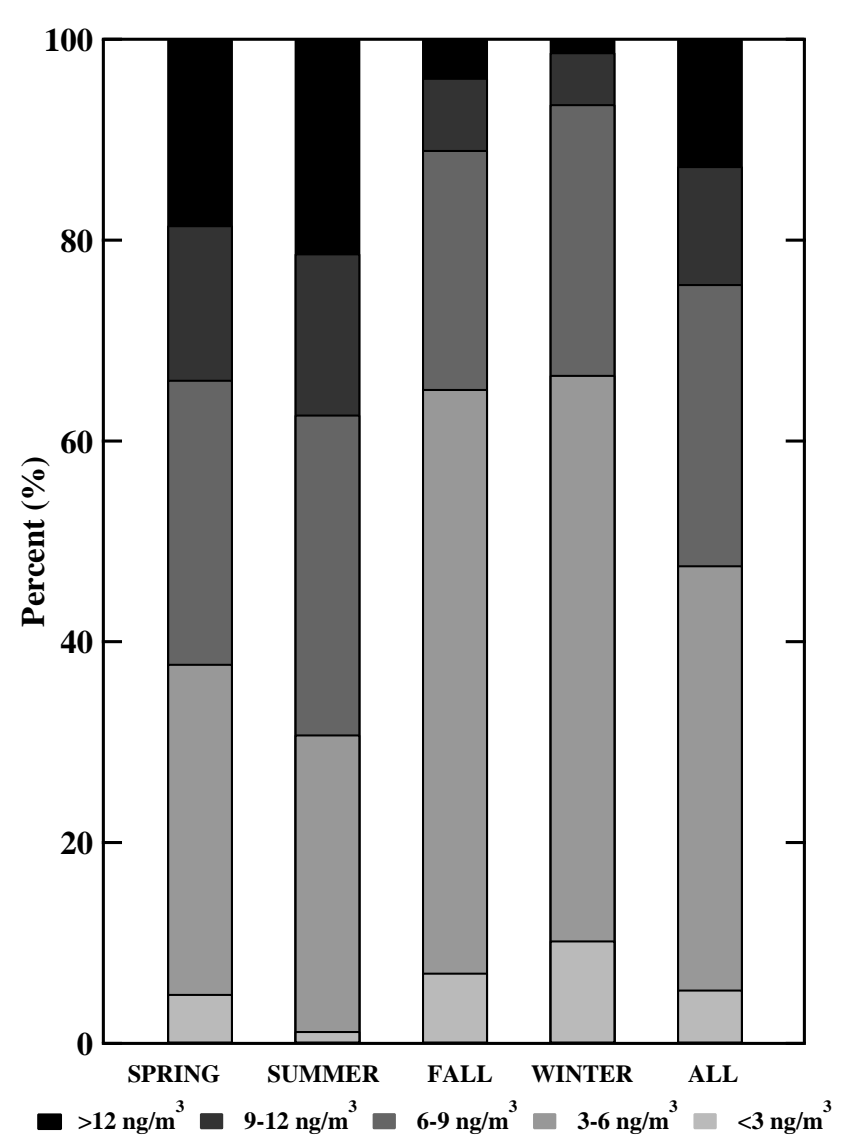

Fig. 5. Frequency of different concentration interval in each season.

centrations (TGM $>12 \mathrm{ng} \mathrm{m}^{-3}$ ) appeared more frequently in summer and spring, comprising around $20 \%$ of all data in that season. The cleanest conditions (TGM $<3 \mathrm{ng} \mathrm{m}^{-3}$ ) were $\sim 10 \%$ of the data in winter, in comparison with only $\sim 1.2 \%$ in summer.

In addition, the TGM seasonal pattern from our site appeared to be opposite of what other sites in China and worldwide experienced. Especially in China, limited long-term measurements of TGM suggested annual maximums in winter and minimums in summer (Feng et al., 2004, 2003; Ci et al., 2011; Fu et al., 2008, 2010; Wan et al., 2009). Previous studies speculated that the serious contamination in winter resulted from locally and regionally increased coal combustion for domestic heating and slower removal from the atmosphere, and that the minimum in summer was due to higher $\mathrm{OH}$ concentrations leading to faster oxidation of GEM (Warneck, 1988). The summer minimum was also attributed to the annual maximum wet and dry deposition observed during the summer (Jensen and Iverfeldt, 1994).

However, the measurement sites reported in China are all in the north or mountainous areas with a cold winter climate, which include Guiyang, Changchun, Mt. Changbai, Mt. Leigong. The subtropical climate in Nanjing means that traditionally domestic heating in winter is not necessary, 
Table 2. Summary of TGM measurements in China and other countries.

\begin{tabular}{|c|c|c|c|c|c|}
\hline Locations & Classification & Time & Duration & TGM $\left(\mathrm{ng} \mathrm{m}^{-3}\right)$ & Reference \\
\hline Beijing & Urban & $05.1,4,7,10$ & 60 days & $4.9-8.3$ & Wang et al. (2007) \\
\hline Beijing & Urban & $98.1,2,9$ & 17 days & $8.1-34.9$ & Liu et al. (2002) \\
\hline Changchun, Jilin & Urban & $99.7-00.7$ & $1 \mathrm{yr}$ & $13.5-25.4$ & Fang et al. (2004) \\
\hline Chongqing & Urban & $06.8-07.9$ & & $6.74 \pm 0.37$ & Yang et al., 2009 \\
\hline Guangzhou, Guangdong & Urban & 05.1 & 2 weeks & $13.5 \pm 7.1$ & Wang et al. (2009) \\
\hline Gui Yang, Guizhou & Urban & $08.90-09.7$ & 6 months & $7.4 \pm 4.8,6.2 \pm 5.1$ & Liu et al. (2011) \\
\hline Gui Yang, Guizhou & Urban & $01.10-02.10$ & $1 \mathrm{yr}$ & $8.40 \pm 4.87$ & Feng et al. (2004) \\
\hline Gui Yang, Guizhou & Urban & $00.4-01.11$ & 100 days & $5.20-8.56$ & Feng et al. (2003) \\
\hline Ningbo, Zhejiang & Urban & $07.10,08.1$ & 12 days & $3.79 \pm 1.29$ & Nguyen et al. (2011) \\
\hline Shanghai & Urban & $09.8-9$ & 1 month & $2.7 \pm 1.7$ & Friedli et al. (2011) \\
\hline Beijing & Suburan & $98.1,2,9$ & 25 days & $5.3-12.4$ & Liu et al. (2002) \\
\hline Changchun, Jilin & Suburan & $99.7-00.8$ & & $9.1-15.4$ & Fang et al. (2004) \\
\hline Chengshantou, Shandong & Rural/Coastal & $07.7-09.5$ & 55 days & $2.31 \pm 0.74$ & Ci et al. (2011) \\
\hline Chengshantou, Shandong & Rural/Coastal & $07.7,07.10$ & 9 days & $2.07 \pm 0.91$ & Nguyen et al. (2011) \\
\hline Mt. Gongga, Sichuan & Rural & $06.4-07.6$ & $1 \mathrm{yr}$ & $3.90 \pm 1.20$ & Fu et al. (2009) \\
\hline Beijing & Rural & $98.2,9$ & 9 days & $2.5-5.0$ & Liu et al. (2002) \\
\hline Jiaxing, Zhejiang & Rural & 09.5 & 2 weeks & $5.4 \pm 4.1$ & Wang et al. (2008) \\
\hline Mt. Changbai, Jilin & Rural & $05.8-06.7$ & $1 \mathrm{yr}$ & $3.58 \pm 1.78$ & Wan et al. (2009) \\
\hline Mt. Changbai, Jilin & Rural & $08.10-10.10$ & $2 \mathrm{yr}$ & $1.60 \pm 0.51$ & Fu et al. (2012) \\
\hline Mt. Gongga, Sichuan & Rural & $05.5^{\sim} 06.6$ & $1 \mathrm{yr}$ & $3.98 \pm 1.62$ & Fu et al. (2008) \\
\hline Mt. Leigong, Guizhou & Rural & $08.5-09.5$ & $1 \mathrm{yr}$ & $2.80 \pm 1.51$ & Fu et al. (2010) \\
\hline Waliguan, Qinghai & Rural & $05.8,05.12$ & 4 weeks & $0.6 \pm 0.08,1.7 \pm 1.1$ & Wang et al. (2006) \\
\hline Wanqingsha, Guangdong & Rural & $08.11-12$ & 1 month & $2.94 \pm 2.02$ & Zheng et al. (2011) \\
\hline Yellow Sea & Ocean & $07.9-08.1$ & 13 days & $1.82-2.43$ & Nguyen et al. (2011) \\
\hline Nanjing, Jiangsu & Urban & $11.1-11.12$ & $1 \mathrm{yr}$ & $7.94 \pm 6.99$ & This Study \\
\hline Mexico City, Mexico & Urban & 06.3 & 17 days & $7.2 \pm 4.8$ & Rutter et al. (2009) \\
\hline Zingst, Germany & Rural/Coastal & 98-04 & $5 \mathrm{yr}$ & 1.66 & Kock et al. (2005) \\
\hline Seoul, Korea & Urban & $97.9-02.6$ & $5 \mathrm{yr}$ & 5.06 & Kim et al. (2005) \\
\hline New Hampshire, USA & Rural/Coastal & $03-07$ & $4 \mathrm{yr}$ & $1.13-1.60$ & Mao et al. (2008) \\
\hline Reno, USA & Urban & 04-07 & $4 \mathrm{yr}$ & 1.60 & Peterson et al. (2009) \\
\hline Weeks Bay, USA & Urban & $05.4-06.1$ & 10 months & 1.62 & Engle et al. (2008) \\
\hline
\end{tabular}

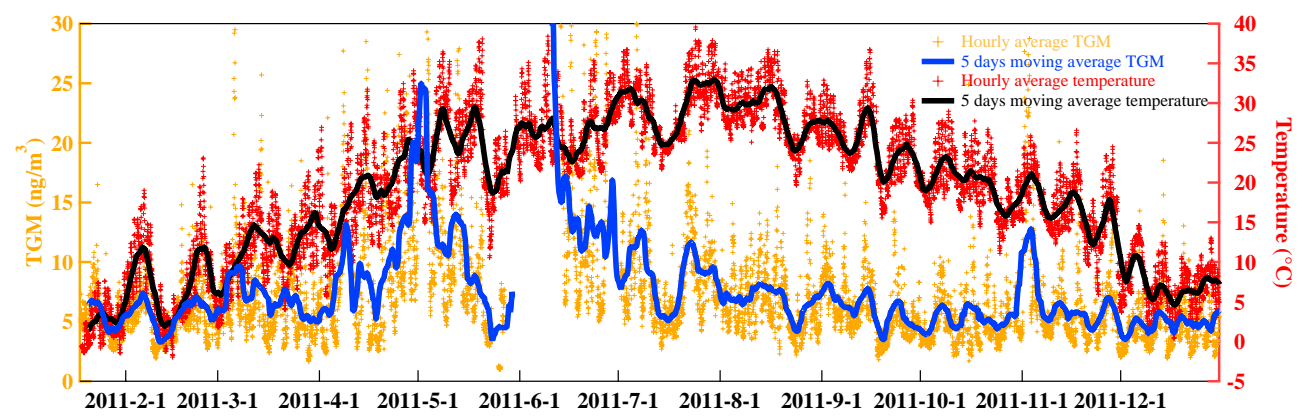

Fig. 6. Time series of TGM concentration and temperature in Nanjing during study period.

resulting in relatively constant coal consumption throughout the year in this area. Two short-term field campaigns in Beijing (Liu et al., 2002) and Chongqing (Li et al., 2010) showed seasonal patterns similar to our study. The factors which controlled the seasonal characteristics of mercury in our site will be discussed in the following section.

\subsubsection{Analysis of potential controlling factors}

Natural sources of mercury include evasion of geologically bound mercury from vegetation, soils, lakes, rivers, oceans, and volcanoes, as well as the re-emission of previously deposited mercury (Schroeder and Munthe, 1998). Previous research has paid more attention to anthropogenic emissions of mercury. However, Shetty et al. (2008) estimated with 


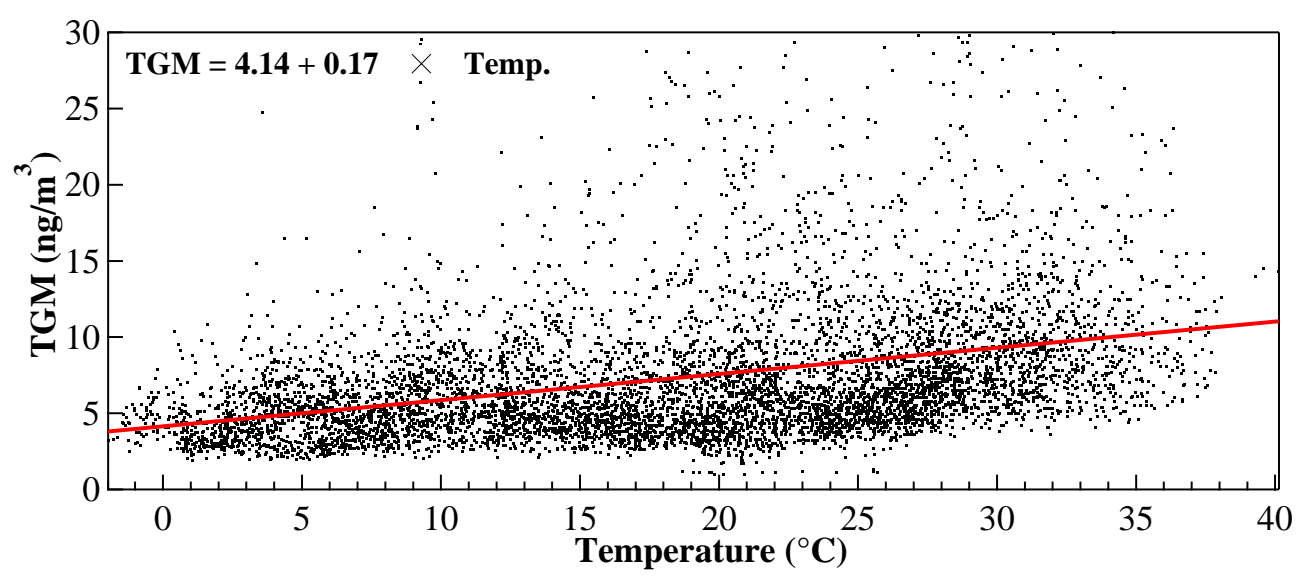

Fig. 7. Correlation between 5-day moving average TGM concentration and temperature in Nanjing during the study period $(R=0.43)$.

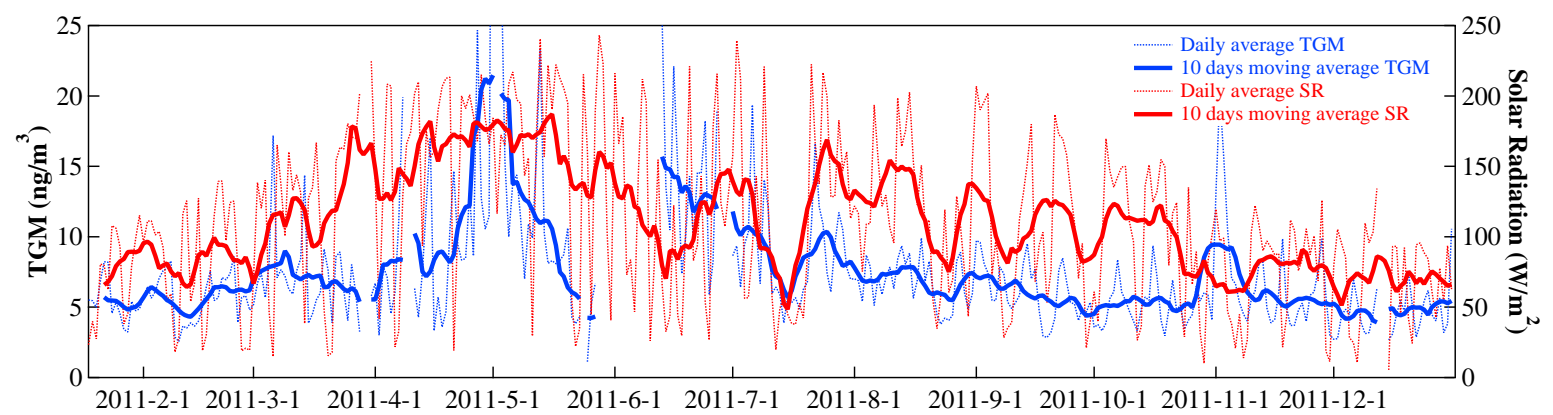

Fig. 8. Time series of TGM concentration and daily averaged solar radiation in Nanjing during study period.

a model that natural mercury emissions in East Asia were $\sim 1.8$ times larger than anthropogenic emissions in summer and were $>10$ times larger in summer than those in winter. Moreover, Nanjing and its surrounding areas are the largest natural emission region during summer in China. According to the data of spatial distribution of mercury concentrations in soil, from the Chinese Environmental Monitoring Center, Nanjing and the regions to its west and south areas contain some of the largest soil mercury concentrations in China (Shetty et al., 2008). Therefore, we propose that in summer, natural sources could make a significant contribution to the high monthly average levels of TGM in Nanjing. However, most sharp peaks were caused by anthropogenic sources probably and this will be discussed further in Sect. 3.4.2.

Natural emissions of mercury correlate with temperature and solar radiation especially over soil surfaces (Leonard et al., 1998; Carpi and Lindberg, 1998). Some researchers speculate that higher TGM may be attributed to thermally and/or photochemically mediated release from soil (Poissant and Casimir, 1998; Sigler and Lee, 2006). Poissant and Casimir (1998) found the mercury flux from grass covered soil was relatively constant at $2-3 \mathrm{ng} \mathrm{m}^{-2} \mathrm{~h}^{-1}$ in the temperature range of $10-20^{\circ}$ and could rise to $7-8 \mathrm{ng} \mathrm{m}^{-2} \mathrm{~h}^{-1}$ when temperature was between $20^{\circ}$ and $30^{\circ}$. The correlation of TGM concentration and temperature at our site was exam- ined. Figure 6 shows the time series of TGM concentration and temperature along with the 5 day moving averages during the measurement period. Moving average TGM concentration versus temperature exhibited a positive correlation with a correlation coefficient $(R)$ of 0.43 . Figure 7 shows a slope value of $0.17 \mathrm{ng} \mathrm{m}^{-3 \circ-1}$.

Several studies concluded that the dominant factor affecting natural mercury emissions from soil was solar radiation (Carpi and Lindberg, 1997; Wallschlager et al., 1999; Gustin et al., 1999; Scholtz et al., 2003). In order to avoid interference from the diurnal variation in radiation, we utilized the daily average values. A positive correlation between solar radiation and TGM concentration was found (Fig. 8), with a correlation coefficient $(R)$ of 0.53 , which was higher than the correlation between temperature and TGM concentration.

The data set of daily average radiation was divided into five subsets. Then, the TGM concentration for each subset was calculated (Fig. 9). It is clear that the median, 25th and 75 th percentile values increased with solar radiation flux. In addition, when solar radiation was strong (daily average $>140 \mathrm{~W} \mathrm{~m}^{-2}$ ), TGM concentrations were significantly larger by a factor of 1.3-1.7 than those times with lower radiation level. This indicates solar radiation could be an important factor contributing to high TGM levels in summer. Two hypotheses were proposed for the mechanisms driving 


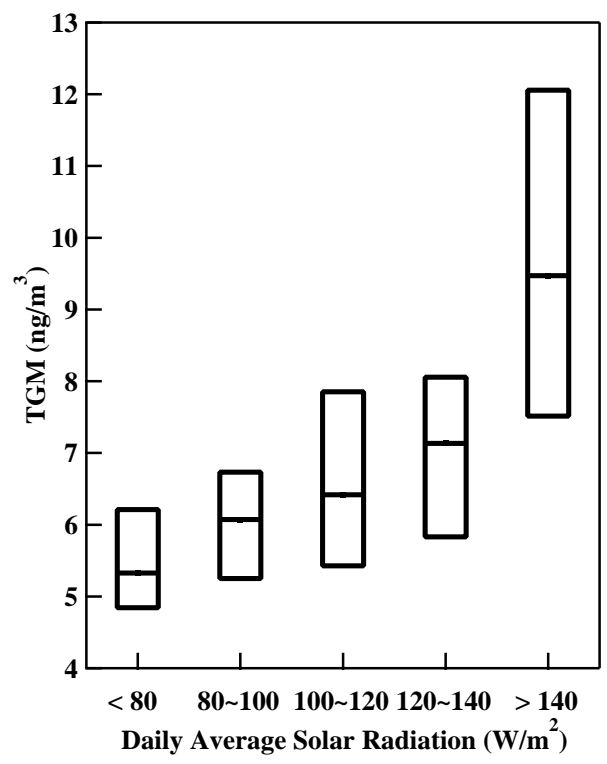

Fig. 9. Relationship between TGM concentration and daily average solar radiation in Nanjing.

the positive impact of solar radiation on mercury emissions from soil. First, Zhang et al., (2001) suggested that light may reduce the apparent activation energy of the mercury emission process. Second, Carpi and Lindberg (1997) and Gustin et al. (2002) suggested that light may affect the reduction of divalent mercury in soil to GEM, which is subsequently volatilized to the atmosphere.

The large amount of the mercury in soil around Nanjing and the surrounding region probably were reemitted from the terrestrial system. $\mathrm{CO}$ has a significant anthropogenic source and it is considered as an indicator of anthropogenic emissions (Mao et al., 2008). Thus, it can be insightful to examine the relationship between TGM concentrations and anthropogenic emissions by comparing them with $\mathrm{CO}$ concentrations. However, our measurements did not suggest a large seasonal variability in CO (Fig. 10), unlike in TGM. Moreover, we found that CO and TGM were correlated with $R=0.78$ in winter compared to $R=0.35$ in summer (Fig. 11). This indicated that CO and TGM concentrations were affected by similar sources of anthropogenic emission in winter. The low correlation coefficient in summer suggested an important role of natural sources of TGM in summer. Of course, the re-volatilized mercury which could be deposited anthropogenic mercury is also regard as natural emission. Our observed TGM/CO ratio in winter was $0.00312 \mathrm{ng} \mathrm{m}^{-3} \mathrm{ppb}^{-1}$ and in summer is 0.00719 , which was close to the TGM/CO ratio of $0.0074 \mathrm{ng} \mathrm{m}^{-3} \mathrm{ppb}^{-1}$ found in a Shanghai plume during the ACE-Asia campaign by Friedli et al. (2004). Jaffe et al. (2005) also suggested ratios for individual Asian transport events ranged with 0.0036$0.0074 \mathrm{ng} \mathrm{m}^{-3} \mathrm{ppb}^{-1}$, with a mean of $0.0056 \mathrm{ng} \mathrm{m}^{-3} \mathrm{ppb}^{-1}$ during Asian transport episodes. However the TGM/CO ra- tio in Nanjing and Asian emission was obviously higher than that observed in America, which was $\sim 0.0020$ in northeast America (Mao et al., 2008) and $\sim 0.0011$ in US industrial events (Weiss-Penzias et al., 2007). This may be caused by different source composition and emission progress. Thus the ratio of TGM/CO appears to be a good tracer of Asian industrial outflow. Additionally, the intercepts of TGM and CO gave the background concentration of TGM in different season. The background concentration was $6.94 \mathrm{ng} \mathrm{m}^{-3}$ in summer, which was notable higher than that in winter of $2.59 \mathrm{ng} \mathrm{m}^{-3}$. Further, annual anthropogenic mercury emission of $4.26 \mathrm{t}$ was estimated based on the ratio of TGM/CO and the emission inventory of $\mathrm{CO}$ in Nanjing (Huang et al., 2011).

\subsection{Diurnal variation}

TGM concentrations in Nanjing exhibited a pronounced diurnal pattern, as shown in Fig. 12, which were averaged over each hour of the whole study period. TGM concentrations showed a sharp increase after sunrise with a peak higher than $8 \mathrm{ng} \mathrm{m}^{-3}$ during 7-10 a.m. The concentration decreased to below $7 \mathrm{ng} \mathrm{m}^{-3}$ in the afternoon and remained at this lower level at night for several hours until early morning. Annual daytime ( 6 a.m. -6 p.m.) averaged TGM concentrations $\left(7.7 \mathrm{ng} \mathrm{m}^{-3}\right)$ were $10.2 \%$ larger than nighttime measurements $\left(6.9 \mathrm{ng} \mathrm{m}^{-3}\right)$. This is consistent with many other urban cases, which report a similar pattern with the daily peak in the morning and decrease in the afternoon (e.g. Friedli et al., 2011; Song et al., 2009; Liu et al., 2011; Li et al., 2011; Mao et al., 2008). However, quite different diurnal patterns were observed at many suburban sites with the daily maximum occurring at 12 p.m. -3 p.m. probably owing to local emissions and transport(e.g. Fu et al., 2010, 2008; Wan et al., 2009; Kuo et al., 2006). Also, several European sites displayed a diurnal pattern with maximum TGM concentrations occurring at night or early in the morning (Lee et al., 1998; Schmolke et al., 1999). These nighttime peaks of TGM concentrations were attributed to mercury emissions from the surface accumulated in the nocturnal inversion layer (Schmolke et al., 1999).

The diurnal fluctuations of TGM result from complex physical and chemical processes including: surface deposition, volatilization from surrounding surfaces, and transport (Kellerhals et al., 2003). In order to understand the diurnal pattern of TGM at our site, variations in meteorological conditions and trace gas concentrations were examined (Fig. 12). The diurnal cycle of TGM can be divided into three segments including the morning increase, the afternoon decrease, and the nighttime nearly constant level. First, the sharp morning increase can probably be attributed to several processes: emission and downward mixing from aloft after sunrise. Increasing solar radiation and temperature (Fig. 12) also can promote the reduction of previously deposited mercury to GEM which is subsequently emitted 


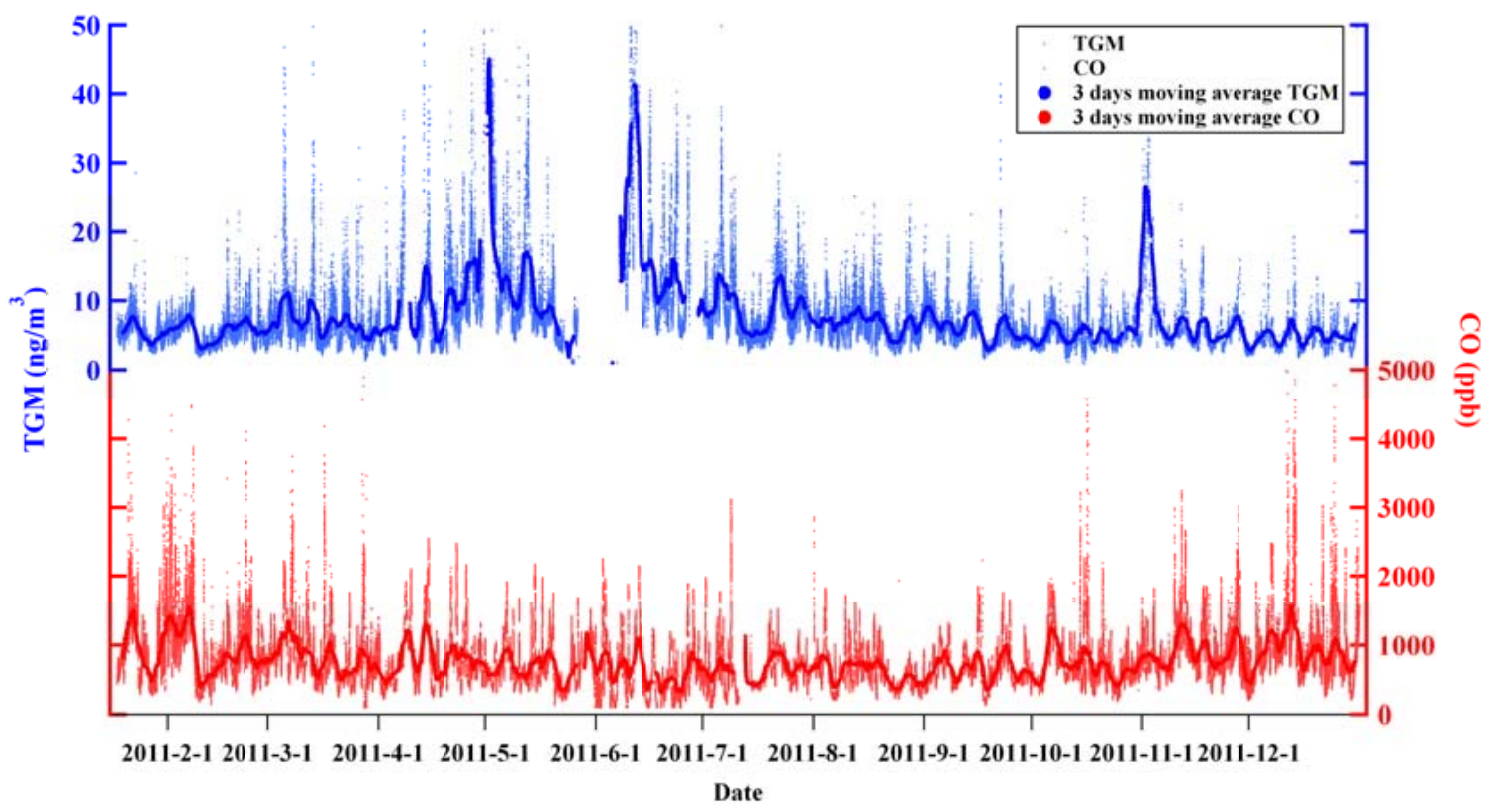

Fig. 10. Time series of TGM and CO concentration in Nanjing during studyperiod.
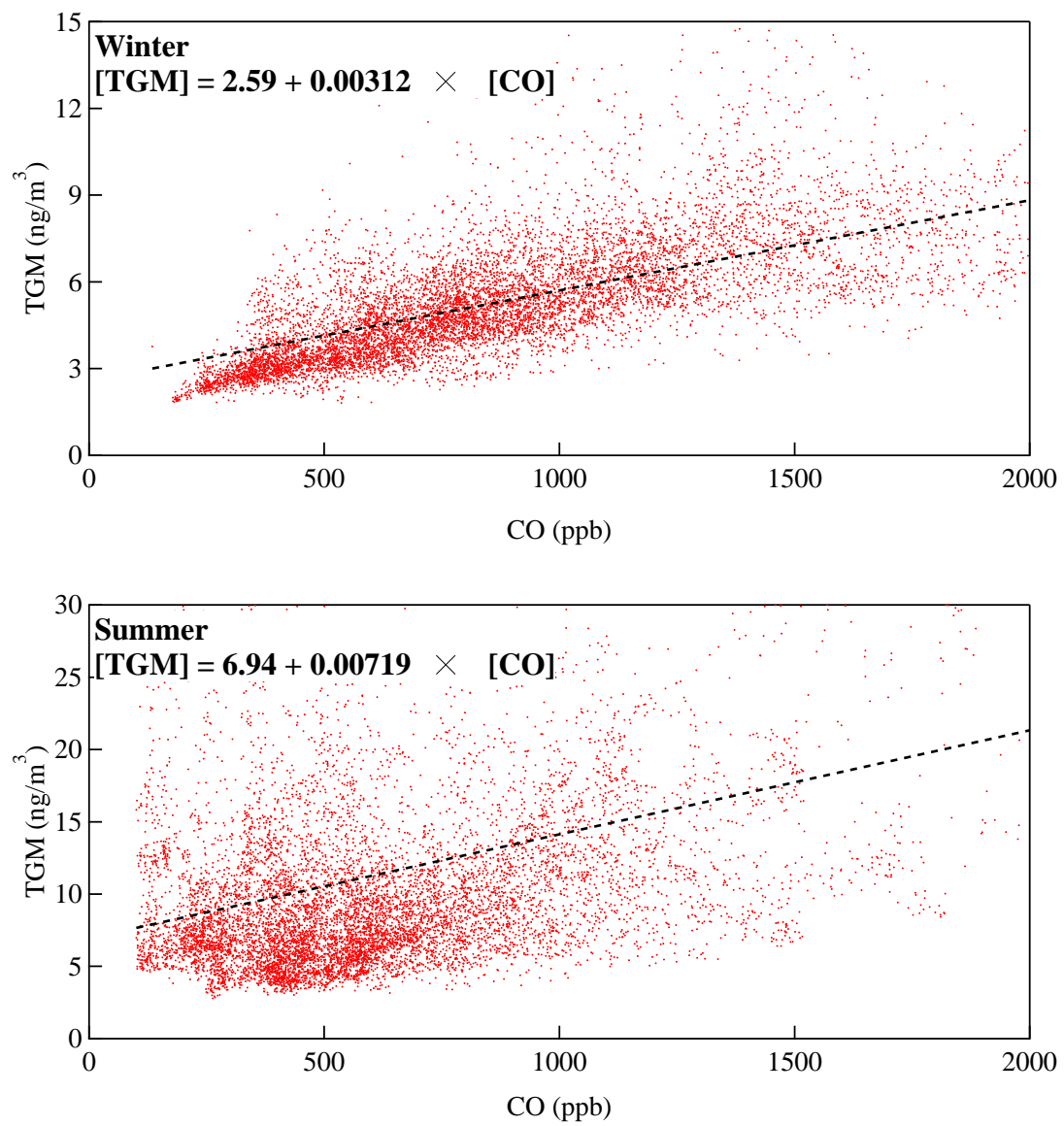

Fig. 11. Correlation between TGM and CO concentrations in winter $(R=0.78)$ and summer $(R=0.35)$. 


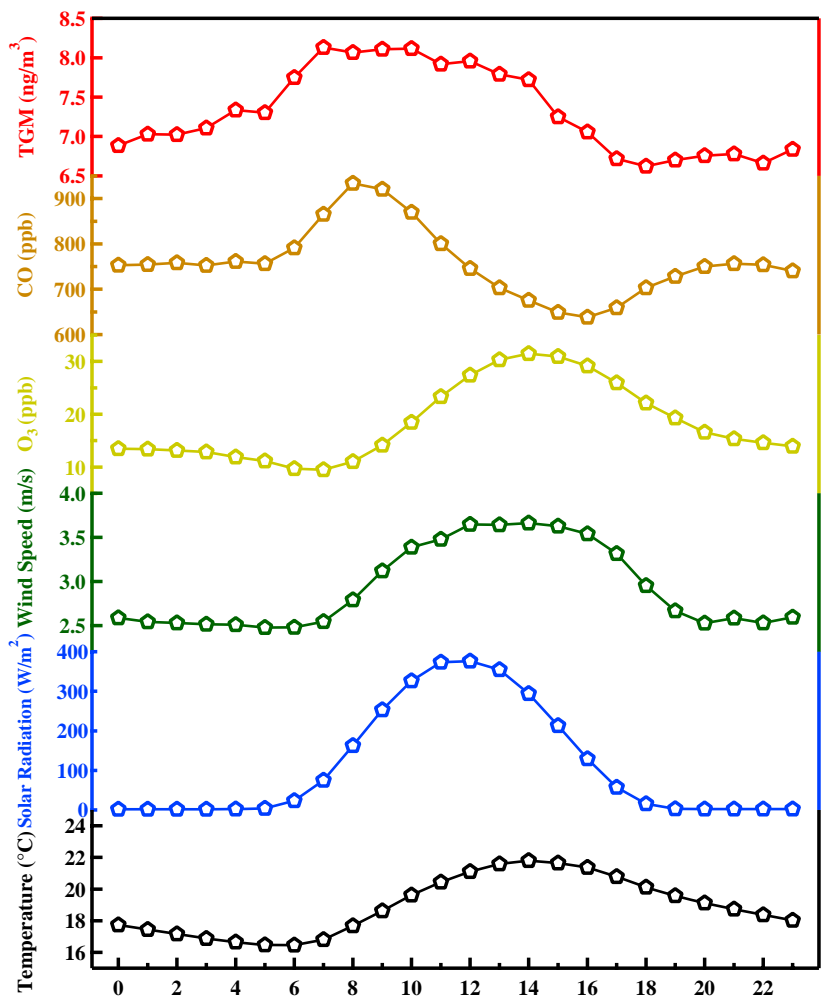

Fig. 12. Annual diurnal variation of TGM concentration, meteorological factor and trace gases.

to the atmosphere (Schroeder and Munthe, 1998). In addition, $\mathrm{CO}$ also showed a diurnal cycle consistent with that of TGM, with a major peak during the morning rush hour suggesting possible contribution from mobile combustion. Some research also suggests the increase in TGM concentrations after sunrise can be ascribed chiefly to mercury revolatilization from abundant dew, which formed due to radiational cooling of the surface at night (Mao et al., 2012; Kim et al., 2010). It was also suggested that as the nocturnal inversion layer collapses, the downward mixing of air masses from aloft may increase the surface TGM level (Stamenkovic et al., 2007; Mao et al., 2008). The drop in TGM concentrations in the afternoon is possibly due to the growth of the boundary layer height caused by thermal mixing. However, TGM concentrations did not decrease as drastically as CO mixing ratios did. The less drastic TGM drop can probably be attributed to the peak in solar radiation and temperature, which increased emissions from natural sources. The lack of nighttime variation implies that TGM was removed from the boundary layer at a rate comparable to emissions.

Further, there was noticeable variation in the seasonally averaged diurnal cycles (Fig. 13). The largest diurnal variation was observed in spring with amplitude of $3.7 \mathrm{ng} \mathrm{m}^{-3}$. The fluctuation was much less in winter with amplitude of $0.9 \mathrm{ng} \mathrm{m}^{-3}$. The lower amplitude in winter was likely attributable to the lower general level of TGM concentration and relatively less influence of natural sources. All diurnal cycles showed a slight increase at night except in summer. This was probably caused by better diffusion conditions during summer nights due to the less frequent nocturnal inversion. In addition, the daily peak in TGM concentrations always occurred at $11 \mathrm{a} . \mathrm{m}$. during summer which was later than during other seasons. This delayed peak was possibly associated with longer-lasting, strong solar radiation inducing extended evasion from soils.

\subsection{Cluster analysis of air mass}

\subsubsection{Relationship between TGM concentration and wind}

The hourly averaged TGM concentration data were grouped into eight clusters for every change of $45^{\circ}$ in wind direction (Fig. 14). During the measurement period, the prevailing wind was from the north and east with a relative frequency of $31 \%$ and $17 \%$, respectively. In Fig. 15, the calculated frequency distribution of five TGM levels in each $45^{\circ}$ slice of wind direction was shown. Distributions of TGM concentrations in each of the wind direction were quite different from each other. The lowest TGM levels $\left(<3 \mathrm{ng} \mathrm{m}^{-3}\right)$ mainly occurred under the northwesterly to northeasterly wind. In contrast, wind from the south, southeast and southwest, which was not predominant, typically accompanied the highest TGM levels (higher than $12 \mathrm{ng} \mathrm{m}^{-3}$ ). We define a TGM pollution episode when the concentration exceeded $6.0 \mathrm{ng} \mathrm{m}^{-3}$ which is close to the annual median value of $6.2 \mathrm{ng} \mathrm{m}^{-3}$. Pollution episodes seemed to occur under southwesterly to southeasterly winds with probabilities all over $65 \%$. Probability even reached $79 \%$ when wind was from the south. This indicated the predominate influence from regional sources in these directions.

The relationship between TGM concentration and wind speed in each wind direction was examined. In general, Fig. 14 shows atmospheric pollutant concentrations tended to be enhanced with decreasing wind speeds due to less ventilation except in the southwestern direction. This tendency was more distinct, evidenced in larger $\mathrm{R}$ values, when the wind came from north, northeast, east and southeast. Wind speed and TGM were hardly correlated under southern, southwestern and western winds. We observed that the fitted equation and correlation coefficient of the southern and western directions did not pass the significance test at a significance level of $95 \%$. This difference further illustrated that the fact that winds from the southern or near southern direction would advect richer TGM concentrations in comparison with relative cleaner air masses from the north and east.

\subsubsection{Analysis of air mass back trajectories}

In order to gain insight into the influence of long-range transport on TGM concentrations in Nanjing, five-day 6-hourly 

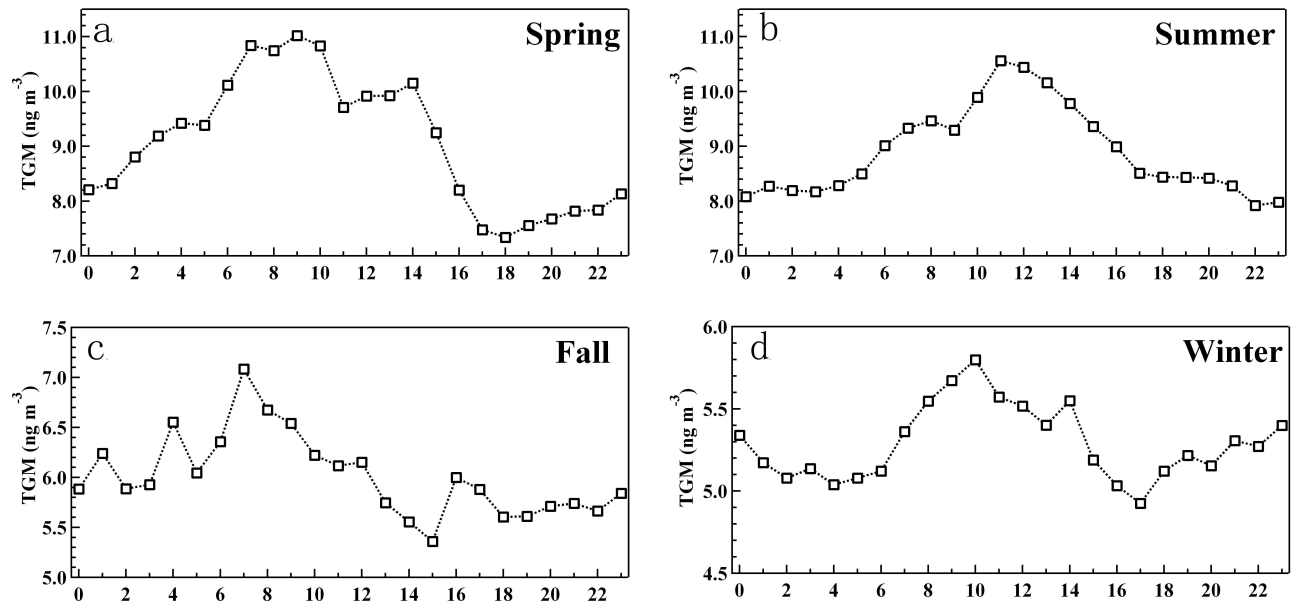

Fig. 13. The average diurnal variation of TGM in (a) spring, (b) summer, (c) fall, (d) winter.

backward trajectories were simulated using HYSPLIT during the study period starting from the location of our site. We calculated 1391 back trajectories that were grouped into six clusters, which are shown in Fig. 16. Clusters 1 and 3 both showed air masses originating from Siberia and Mongolia, respectively, passing over Northern China. These two represented cold air masses traveling via fast flows over long distances. Clusters 2 and 4 were of larger frequency (>20\%). Cluster 2 consisted of air masses from Northern China and cluster 4 came from Korea. However, these two clusters of back trajectories both passed over the East China Sea before arriving in Nanjing. We considered them as land-oceanic air masses. Cluster 5 was the shortest in distance with a frequency of $14 \%$, classified as local air masses, indicating slow-moving air masses over East China. Air masses in cluster 6 originated from the South China Sea, and then passed over south and central China.

Ranges of TGM levels in the five clusters were quite different. The average, $25 \%$ and $75 \%$ percentile concentrations of TGM in each cluster were calculated and are shown in Fig. 17. The largest average concentration of $11.9 \mathrm{ng} \mathrm{m}^{-3}$ was found in local air masses (cluster 5). The concentrations in southern air masses (cluster 6), with an average of $9.82 \mathrm{ng} \mathrm{m}^{-3}$, were higher than those in oceanic air masses (cluster 2 and cluster 4). The cleanest air masses were found coming from the north in clusters 1 and 3 with averages of 4.7 and $5.9 \mathrm{ng} \mathrm{m}^{-3}$ respectively. Probably the most important sources of mercury for Nanjing are local emissions and long-range transport from the south.

Some extremely serious TGM pollution episodes were observed during the study period with peaks exceeding $40 \mathrm{ng} \mathrm{m}^{-3}$ (Fig. 2). Three-day HYSPLIT backward trajectories in 12 TGM pollution episodes (Fig. 18) showed that 9 of the total trajectories passed over the south of Nanjing. Among them, 7 trajectories started from the south and southwest of China, and two (5 March and 11 April) originated in the north. Moreover, air masses in two episodes (27 April and 1 May) were transported over long distances from the southwest and entered Nanjing from the north. The episode of 3 November was exceptional with air masses coming from Korea and passing through the East China Sea. This rare trajectory probably caused the unique high peak in winter. The most significant sources of mercury are most likely located south of Nanjing. Additionally, some sources in the southwest and south of China may also contribute to high TGM peaks in Nanjing via long range transport.

\section{Summary}

A comprehensive analysis of the characteristics of TGM in Nanjing was conducted. Nearly one-year of continuous measurement of TGM, meteorological conditions, and trace gases were made at our site. The average concentration for TGM was $7.9 \pm 7.0 \mathrm{ng} \mathrm{m}^{-3}$ with a large range of $0.8 \sim 180 \mathrm{ng} \mathrm{m}^{-3}$ during the whole study period. The concentration of TGM in Nanjing is significantly elevated compared to global background values, but comparable with the measurements from other cities in China. Total TGM concentrations followed a typical lognormal pattern with more than half of the total measurements between 3 and $7 \mathrm{ng} \mathrm{m}^{-3}$. Episodes with extremely high TGM concentrations were also observed, but only made up a small portion of the TGM data set, with $4.10 \%$ exceeding $20 \mathrm{ng} \mathrm{m}^{-3}$.

A distinct seasonal distribution of TGM concentrations during the study period was found, with maxima in summer and minima in winter. The most serious episodes (TGM concentration larger than $12 \mathrm{ng} \mathrm{m}^{-3}$ ) appeared more frequently in summer and spring, which composed approximately $20 \%$ of all data in those seasons. This seasonal pattern stands in contrast to most measurements in other locations. We conjecture, natural sources make great contributions in summer to the high level of TGM in Nanjing. Nanjing and the 

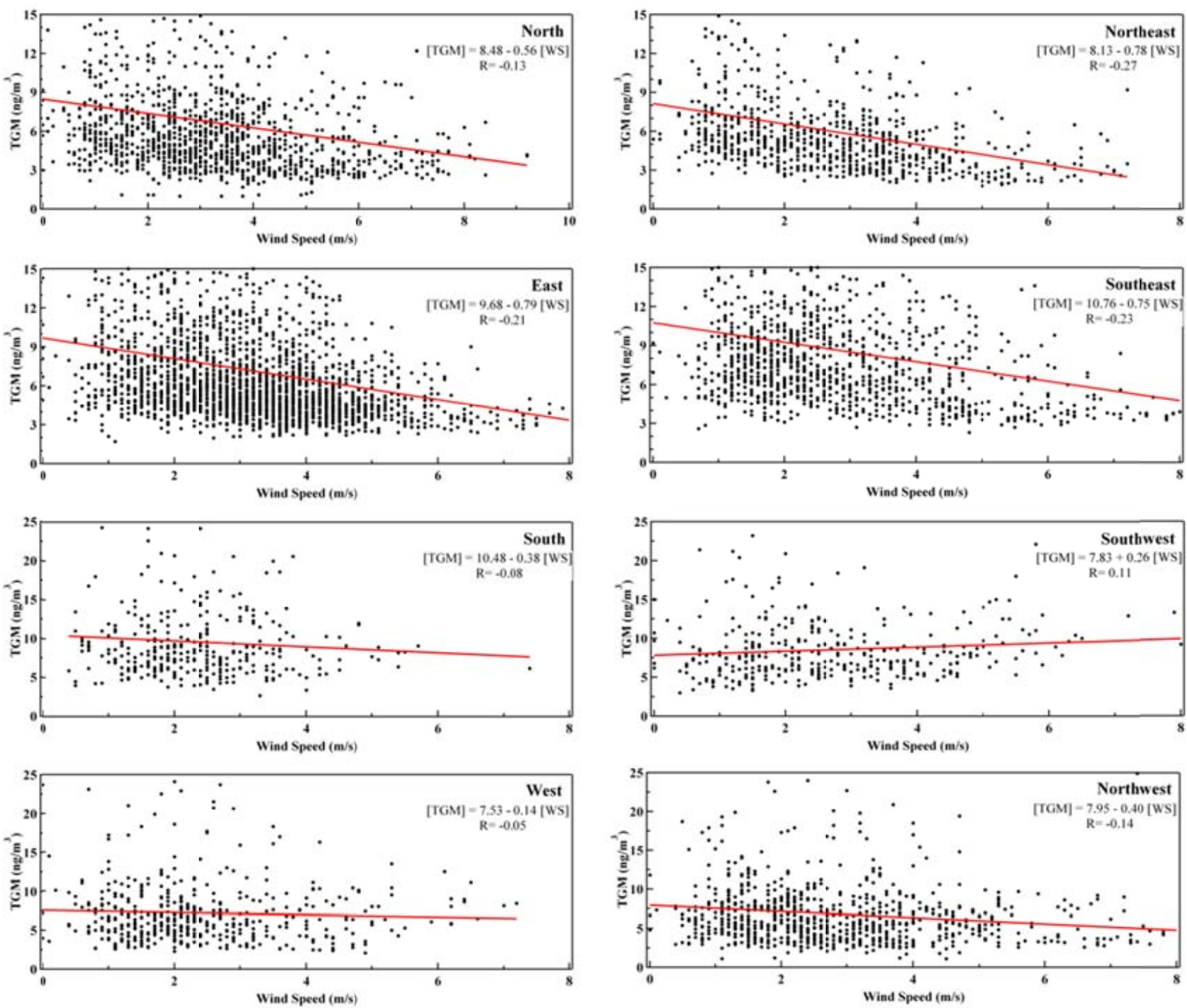

Fig. 14. Relationship between TGM concentration and wind speed in each wind direction.

surrounding area is one of the largest natural emission regions in China with large seasonal variation. Positive correlations between temperature, solar radiation and TGM concentrations were found over the study period. In addition, the conspicuous difference between correlation coefficients of $\mathrm{CO}$ and TGM concentrations in winter and summer likely indicate the impact of different anthropogenic and natural sources in the cold and warm seasons respectively.

TGM concentrations in Nanjing exhibited a pronounced diurnal pattern with a peak concentration of greater than $8 \mathrm{ng} \mathrm{m}^{-3}$ during $7 \sim 10$ a.m. Annual daytime (6a.m. $\sim 6$ p.m.) averaged TGM concentrations were $10.2 \%$ larger than averaged nighttime levels. The diurnal fluctuation of hourly TGM represented the effects of multiple factors including $\mathrm{O}_{3}$ concentrations, wind speed, solar radiation and temperature. Moreover, each seasonally average diurnal cycle of TGM exhibited noticeably different patterns due to different diffusion condition and nocturnal inversions. The largest diurnal variations were observed in spring, compared with insignificant diurnal variations in winter.

The relationship between TGM concentrations and wind was studied. The lowest TGM levels (lower than $3 \mathrm{ng} \mathrm{m}^{-3}$ ) mainly occurred during northern, northeastern and northwestern wind. In contrast, wind from the south, southeast and southwest, which is not the prevailing wind direction, corresponded to the largest TGM levels (higher than $12 \mathrm{ng} \mathrm{m}^{-3}$ ). When Nanjing was experiencing north, northeast, east, and southeast winds, TGM concentration decreased with increasing wind speed. By contrast, the effect of wind speed was negligible when Nanjing was under southern, southwestern 


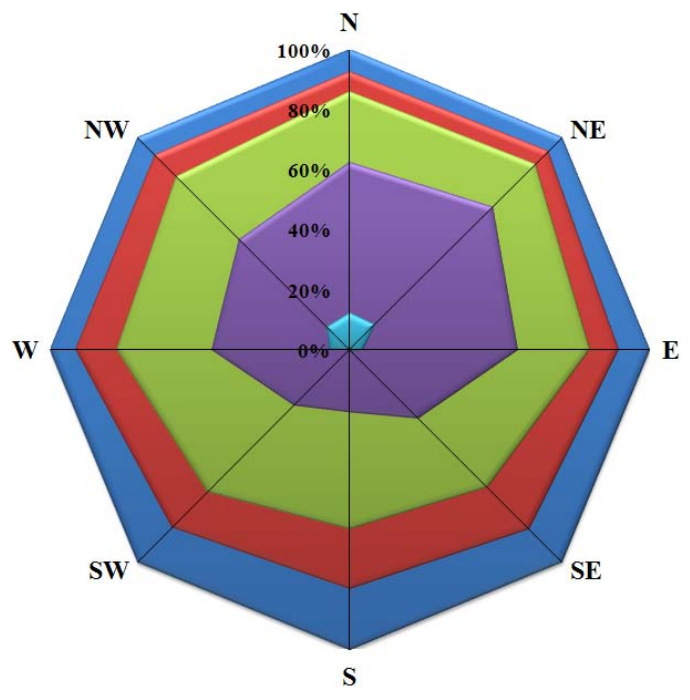

Fig. 15. The frequency distribution of TGM levels during 18 January and 31 December 2011.

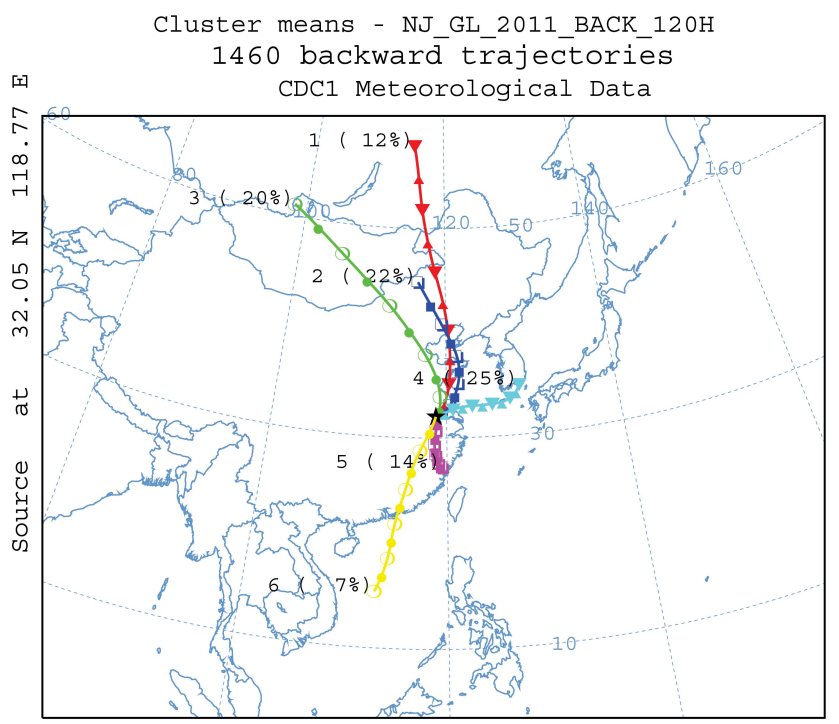

Fig. 16. Clusters of 5-day back trajectories arriving at the study site simulated by HYSPIT model (1: red, 2: deep blue, 3: green, 4: light blue, 5: purple, 6: yellow).

and western wind patterns. In addition, five-day air mass backward trajectories from our site were simulated by HYSPLIT every $6 \mathrm{~h}$. The largest average TGM concentration of $11.9 \mathrm{ng} \mathrm{m}^{-3}$ corresponded to local air masses. The cleanest air masses, with average TGM concentration of 4.7 and $5.9 \mathrm{ng} \mathrm{m}^{-3}$, were found to come from the north with high transport speed. Local source and sources in the south and southwest of China probably contributed most to high TGM concentration in Nanjing.

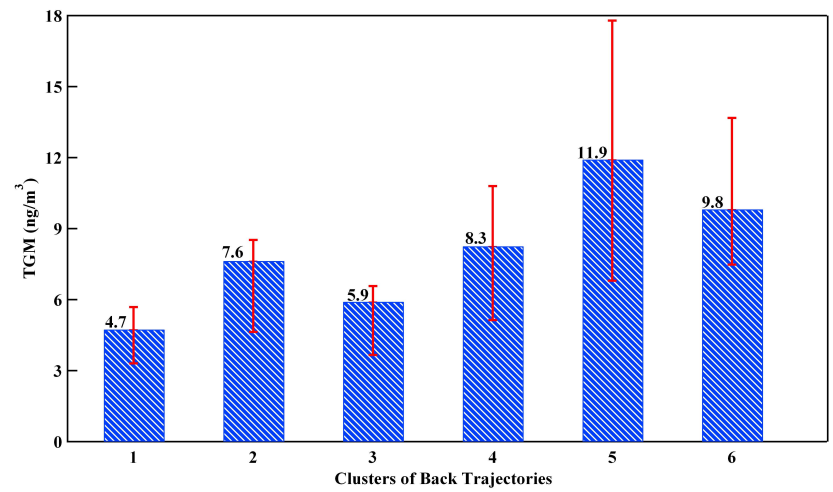

Fig. 17. The average, $25 \%$ and $75 \%$ percentile TGM concentrations in each cluster of back trajectories.

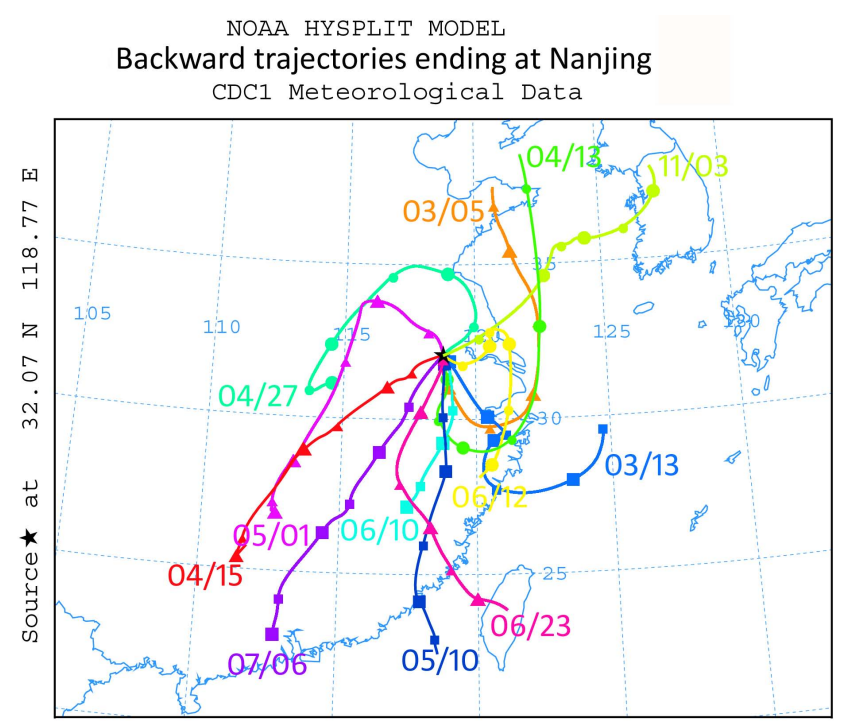

Fig. 18. Three-day back trajectories in 12 serious TGM pollution episodes during the study period simulated by HYSPLIT.

Acknowledgements. The authors would like to thank all members in the AERC (atmospheric environment research center) of Nanjing University for maintaining instruments and express their sincere appreciation to LanXin who provided helpful comments and suggestions. We also acknowledge Environmental Monitoring Center of Nanjing for providing data of radiation and NOAA for HYSPLIT model. This work was supported by the National Key Basic Research Development Program of China (2011CB403406, 2010CB428503), the National Special Fund for the Weather Industry (GYHY201206011), the Specialized Research Fund for the Doctoral Program of Higher Education of China 20110091110010, the Scientific research foundation of graduate school of Nanjing University (2012CL09) and A project Funded by the Priority Academic Program Development of Jiangsu Higher Education Institutions (PAPD).

Edited by: R. Ebinghaus 


\section{References}

Aspmo, K., Temme, C., Berg, T., Ferrari, C., Gauchard, P. A., Fain, X., and Wibetoe, G.: Mercury in the atmosphere, snow and melt water ponds in the North Atlantic Ocean during Arctic summer, Environ. Sci. Technol., 40, 4083-4089, 2006.

Carpi, A. and Lindberg, S. E.: Sunlight-mediated emission of elemental mercury from soil amended with municipal sewage sludge, Environ. Sci. Technol., 31, 2085-2091, 1997.

Carpi, A. and Lindberg, S. E.: Application of a Teflon dynamic flux chamber for quantifying soil mercury flux: Test and results over background soil, Atmos. Environ., 32, 873-882, 1998.

Ci, Z., Zhang, X., Wang, Z., and Niu, Z.: Atmospheric gaseous elemental mercury (GEM) over a coastal/rural site downwind of East China Temporal variation and long-range transport, Atmos. Environ., 45, 2480-2487, 2011.

Engle, M. A., Tate, M. T., Krabbenhoft, D. P., Kolker, A., Olson, M. L., Edgerton, E. S., DeWild, J. F., and McPherson, A. K.: Characterization and cycling of atmospheric mercury along the central US Gulf Coast, Appl. Geochem., 23, 419-437, 2008.

Fang, F. M., Wang, Q. C., and Li, J. F.: Urban environmental mercury in Changchun, a metropolitan city in Northeastern China source, cycle, and fate, Sci. Total Environ., 330, 159-170, 2004.

Feng, X., Shang, L., Wang, S., Tang, S., and Zheng, W.: Temporal variation of total gaseous mercury in the air of Guiyang, China, J. Geophys. Res., 109, D03303, doi:10.1029/2003JD004159, 2004.

Feng, X., Tang, S., Shang, L., Yan, H., Sommar, J., and Lindqvist, O.: Total gaseous mercury in the atmosphere of Guiyang, PR China, Sci. Total Environ., 304, 61-72, 2003.

Fitzgerald, W. F., Engstrom, D. R., Mason, and R. P., Nater, E. A.: The case for atmospheric mercury contamination in remote areas, Environ. Sci. Technol. 32, 1-7, 1998.

Friedli, H. R., Arellano Jr., A. F., Geng, F., Cai, C., and Pan, L.: Measurements of atmospheric mercury in Shanghai during September 2009, Atmos. Chem. Phys., 11, 3781-3788, doi:10.5194/acp-11-3781-2011, 2011.

Fu, X. W., Feng, X., Dong, Z. Q., Yin, R. S., Wang, J. X., Yang, Z. R., and Zhang, H.: Atmospheric gaseous elemental mercury (GEM) concentrations and mercury depositions at a high-altitude mountain peak in south China, Atmos. Chem. Phys., 10, 24252437, doi:10.5194/acp-10-2425-2010, 2010.

Fu, X., Feng, X., Wang, S., Rothenberg, S., Shang, L., Li, Z. and Qiu, G.: Temporal and spatial distributions of total gaseous mercury concentrations in ambient air in a mountainous area in southwestern China implications for industrial and domestic mercury emissions in remote areas in China, Sci. Total Environ., 407, 2306-2314, 2009.

Fu, X. W., Feng, X. B., Zhu, W. Z., Wang, S. F., and Lu, J.: Total gaseous mercury concentrations in ambient air in the eastern slope of Mt. Gongga, South-Eastern fringe of the Tibetan plateau, China. Atmos. Environ., 42, 970-979, 2008a.

Fu, X. W., Feng, X. B., Zhu, W. Z., Zheng, W., Wang, S. F., and $\mathrm{Lu}, \mathrm{J} .:$ Total particulate and reactive gaseous mercury in ambient air on the eastern slope of the Mt. Gongga area. China. Appl. Geochem. 23, 408-418, 2008b.

Fu, X. W., Feng, X., Shang, L. H., Wang, S. F., and Zhang, H.: Two years of measurements of atmospheric total gaseous mercury (TGM) at a remote site in Mt. Changbai area, Northeastern China, Atmos. Chem. Phys., 12, 4215-4226, doi:10.5194/acp12-4215-2012, 2012.
Gabriel, M. C., Williamson, D. G., Brooks, S., and Lindberg, S.: Atmospheric speciation of mercury in two contrasting Southeastern US airsheds, Atmos. Environ., 39, 4947-4958, 2005.

Gustin, M. S. and Lindberg, S. E.: Assessing the contribution of natural sources to the global mercury cycle: The importance of intercomparing dynamic flux measurements, Fresenius J. Anal. Chem., 266, 417-442, 2000.

Gustin, M. S., Biester, H., and Kim, C. S.: Investigation of the light enhanced emission of mercury from naturally enriched substrates, Atmos. Environ., 36, 3241- 3254, 2002.

Gustin, M. S., Rasmussen, P., Edwards, G., Schroeder, W., and Kemp, J.: Application of a laboratory gas exchange chamber for assessment of in situ mercury emissions, J. Geophys. Res., 104, 873-878, 1999.

Huang, C., Chen, C. H., Li, L., Cheng, Z., Wang, H. L., Huang, H. Y., Streets, D. G., Wang, Y. J., Zhang, G. F., and Chen, Y. R.: Emission inventory of anthropogenic air pollutants and VOC species in the Yangtze River Delta region, China, Atmos. Chem. Phys.,11, 4105-4120, doi:10.5194/acp-11-4105-2011, 2011.

Jensen, A. and Iverfeldt, A.: Atmospheric bulk deposition of mercury to the southern Baltic sea area, in Mercury Pollution: Integration and Synthesis, edited by: Watras, C. J. and Huckabee, J. W., 221-229, Lewis, A. F., New York, 1994.

Kellerhals, M., Beauchamp, S., Belzer, W., Blanchard, P., Froude, F., Harvey, B., McDonald, K., Pilote, M., Poissant, L., Puckett, K., Schroeder, B., Steffen, A., and Tordon, R.: Temporal and spatial variability of total gaseous mercury in Canada: results from the Canadian Atmospheric Mercury Measurement Network (CAMNet), Atmos. Environ., 37, 1003-1011, 2003.

Kim, K. H. and Kim, M. Y.: The temporal distribution characteristics of total gaseous mercury at an urban monitoring site in Seoul during 1999-2000, Atmos. Environ., 35, 4253-4263, 2001.

Kim, S. Y.: Continental outflow of polluted air from the U.S. to the North Atlantic and mercury cycling in various 5 Atmospheric environments, Ph.D. dissertation, 114 pp., University of New Hampshire, September 2010.

Kock, H. H., Bieber, E., Ebinghaus, R., Spain, T. G., and Thees, B.: Comparison of long-term trends and seasonal variations of atmospheric mercury concentrations at the two European coastal monitoring stations Mace Head, Ireland, and Zingst, Germany, Atmos. Environ., 39, 7549-7556, 2005.

Kuo, T.H., Chang, C.F., Urba, A., and Kvietkus, K.: Atmospheric gaseous mercury in Northern Taiwan, Sci. Total Environ., 368, 10-18, 2006.

Lee, D. S., Dollard, G. J., and Pepler, S.: Gas-phase mercury in the atmosphere of the United Kingdom, Atmos. Environ., 32, 855864, 1998.

Leonard, T. L., Taylor, G. E., Gustin, M. S., and Fernandez, G. C. J.: Mercury and plants in contaminated soils: 1 . Uptake, partitioning, and emission to the atmosphere, Environ. Toxicol. Chem., 17, 2063-2071, 1998.

Li, J., Yang, Y., Xiao, G., and Wei, S.: Sourcing Contributions of Gaseous Mercury in Indoor and Outdoor Air in China, Environ. Forens., 11, 154-160, 2010

Li, Z., Xia., C., Wang, X., Xiang, Y., and Xie, Z.: Total gaseous mercury in Pearl River Delta region, China during 2008 winter period, Atmos. Environ., 45, 834-838, 2011.

Lindberg, S. E., Meyers, T. P., Taylor, G. E., Turner, R. R., and Schroeder, W. H.: Atmospheric/surface exchange of mercury in a 
forest: results of modeling and gradient approaches, J. Geophys. Res., 97, 2519-2528, 1992.

Lindqvist, O.: Mercury in the Swedish environment: recent research on causes, consequences and corrective methods, Water Air Soil Pollut., 55, 1-261, 1991.

Liu, B., Keeler, G. J., Dvonch, J. T., Barres, J. A., Lynam, M. M., Marsik, F. J., and Morgan, J. T.: Temporal variability of mercury speciation in urban air. Atmos. Environ., 41, 1911-1923, 2007.

Liu, N., Qiu, G. 1., Landis, M. S., Feng, X., Fu, X., and Shang, L.: Atmospheric mercury species measured in Guiyang, Guizhou province, southwest China, Atmos. Res., 100, 93-102, 2011.

Liu, S., Nadim, F., Perkins, C., Carley, R. J., Hoag, G. E., Lin, Y. H., and Chen, L. T.: Atmospheric mercury monitoring survey in Beijing, China, Chemos., 48, 97-107, 2002.

Mao, H. and Talbot, R.: O3 and CO in New England: Temporal variations and relationships, J. Geophys. Res., 109, D21304,doi:10.1029/2004JD004913, 2004.

Mao, H., Talbot, R. W., Sigler, J. M., Sive, B. C., and Hegarty, J. D.: Seasonal and diurnal variations of $\mathrm{Hg}^{\circ}$ over New England. Atmos. Chem. Phys., 8, 1403-1421, 2008, http://www.atmos-chem-phys.net/8/1403/2008/.

Mao, H., Talbot, R., Hegarty, J., and Koermer, J.: Speciated mercury at marine, coastal, and inland sites in New England - Part 2: Relationships with atmospheric physical parameters, Atmos. Chem. Phys., 12, 4181-4206, doi:10.5194/acp-12-4181-2012, 2012.

Mason, R. P., Fitzgerald, W. F., and Morel, F. M.: The biogeochemical cycling of elemental mercury: anthropogenic influences, Geochim. Cosmochim. Acta, 58, 3191-3198, 1994.

Pacyna, E. G., Pacyna, J. M., Steenhuisen, F., and Wilson, S.: Global anthropogenic mercury emission inventory for 2000. Atmos. Environ. 40, 4048-4063, 2006.

Pacyna, E. G., Pacyna, J. M., Sundseth, K., Munthe, J., Kindbom, K., Wilson, S., Steenhuisen, F., and Maxson, P.: Global emission of mercury to the atmosphere from anthropogenic sources in 2005 and projections to 2020, Atmos. Environ., 44, 2487-2499, 2010.

Peterson, C., Gustin, M., and Lyman, S.: Atmospheric mercury concentrations and speciation measured from 2004 to 2007 in Reno, Nevada, USA, Atmos. Environ., 43, 4646-4654, 2009.

Poissant, L. and Casimir, A.: Water-air and soil-air exchange rate of total gaseous mercury measured at background sites, Atmos. Environ., 32, 883-893, 1998.

Poissant, L., Pilote, M., Beauvais, C., Constant, P., and Zhang, H. H.: A year of continuous measurements of three atmospheric mercury species (GEM, RGM and Hg-P) in southern Quebec, Canada, Atmos. Environ., 39, 1275-1287, 2005.

Quan, J., Zhang, X., and Shim, S.: Estimation of vegetative mercury emissions in China, 20, 1070-1074, 2008.

Schmolke, S. R., Schroeder, W. H., Kock, H. H., Schneeberger, D., Munthe, J., and Ebinghaus, R.: Simultaneous measurements of total gaseous mercury at four sites on a $800 \mathrm{~km}$ transect: spatial distribution and short-time variability of total gaseous mercury over central Europe. Atmos. Environ., 33, 1725-1733, 1999.

Scholtz, M. T., Van Heyst, B. J., and Schroeder, W. H.: Modelling of mercury emissions from background soils, Sci. Total Environ., 304, 185-207, 2003.

Schroeder, W. H. and Munthe, J.: Atmospheric mercury - an overview, Atmos. Environ., 32, 809-822, 1998.
Shetty, S., Lin, C., Streets, D., and Jang, C.: Model estimate of mercury emission from natural sources in East Asia, 42, 8674-8685, 2008.

Sigler, J. M., Mao, H., and Talbot, R.: Gaseous elemental and reactive mercury in Southern New Hampshire, Atmos. Chem. Phys., 9, 1929-1942, doi:10.5194/acp-9-1929-2009, 2009.

Slemr, F., Brunke, E. G., Ebinghaus, R., Temme, C., Munthe, J., Wangberg, I., Schroeder, W., Steffen, A., and Berg, T.: Worldwide trend of atmospheric mercury since 1977, Geophys. Res. Lett., 30, 1516-1520, 2003.

Slemr, F., Schuster, G., and Seiler, W.: Distribution, speciation, and budget of atmospheric mercury, J. Atmos. Chem., 3, 407-434, 1985.

Song, X., Cheng, I., and Lu, J.: Annual atmospheric mercury species in Downtown Toronto, Canada, J. Environ. Monit., 11, 660-669, 2009.

Sprovieri, F., Pirrone, N., and Sommar, J.: Mercury speciation in the marine boundary layer along a $6000 \mathrm{~km}$ cruise path around the Mediterranean Sea. Atmos. Environ., 37, suppl. 1, 63-71, 2003.

Sprovieri, F., Pirrone, N., Ebinghaus, R., Kock, H., and Dommergue, A.: A review of worldwide atmospheric mercury measurements, Atmos. Chem. Phys., 10, 8245-8265, doi:10.5194/acp10-8245-2010, 2010.

Stamenkovic, J., Lyman, S., and Gustin, M. S.: Seasonal and diel variation of atmospheric mercury concentrations in the Reno (Nevada, USA) airshed, Atmos. Environ., 41, 6662-6672, 2007.

Street, D. G., Hao, J. M., Wu, Y., Jiang, J. K., Chan, M., and Tian, H. Z.: Anthropogenic mercury emission in China, Atmos. Environ., 39, 7789-7806, 2005.

Temme, C., Slemr, F., Ebinghaus, R., and Einax, J. W.: Distribution of mercury over the Atlantic Ocean in 1996 and 1999-2001, Atmos. Environ. 37, 1889-1897, 2003.

Valente, R. J., Shea, C., Humes, K. L., and Tanner, R. L.: Atmospheric mercury in the Great Smoky Mountains compared to regional and global levels, Atmos. Environ., 41, 1861-1873, 2007.

Valente, R. J., Shea, C., Humes, K. L., and Tanner, R. L.: Atmospheric mercury in the Great Smoky Mountains compared to regional and global levels, Atmos. Environ., 41, 1861-1873, 2007.

Wallschlager, D., Turner, R. R., London, J., Ebinghaus, R., Kock, H. H., Sommar, J., and Xiao, J.: Factors affecting the measurement of mercury emissions from soils with flux chambers, J. Geophys. Res., 104, 859-871,1999.

Wan, Q., Feng, X. B., Lu, J. L., Zheng, W., Song, X. J., Li, P., Han, S. J., and $\mathrm{Xu}, \mathrm{H} .:$ Atmospheric mercury in Changbai Mountain area, northeastern China I: the season distribution pattern of total gaseous mercury and its potential sources, Environ. Res. 109, 201-206, 2009.

Wang, Z. W., Chen, Z. S., Duan, N., and Zhang, X. S.: Gaseous elemental mercury concentration in atmosphere at urban and remote sites in China, J. Environ. Sci., 19, 176-180, 2007.

Wangberg, I., Munthe, J., Berg, T., Ebinghaus, R., Kock, H. H., Temme, C., Bieber, E., et al.: Trends in air concentration and deposition of mercury in the coastal environment of the North Sea Area, Atmos. Environ., 41, 2612-2619, 2007.

Warneck, P.: Chemistry of the Natural Atmosphere, Academic, San Diego, CA, USA, 340 pp., 1988.

Weiss-Penzias, P., Jaffe, D. A. Swartzendruber, P. Hafner, W. Chand, D., and Prestbo, E.: Quantifying Asian and biomass burning sources of mercury using the $\mathrm{Hg} / \mathrm{CO}$ ratio in pollution plumes 
observed at the Mt. Bachelor Observatory, Atmos. Environ., 41, 4366-4379, 2007.

Wu, Y., Wang, S., Streets, D. G., Hao., J., Chan, M. and Jiang, J.: Trends in Anthropogenic Mercury Emissions in China from 1995 to 2003, Environ. Sci. Technol., 40, 5312-5318, 2006.

Wu, Y., Wang, S., Streets, D. G., Hao, J., Chan, M., and Jiang, J.: Trends in anthropogenic mercury emissions in China from 1995 to 2003, Environ. Sci. Technol., 40, 5312-5318, 2006.

Xia, C. H., Xie, Z. Q., Sun, and L. G.: Atmospheric mercury in the marine boundary layer along a cruise path from Shanghai, China to Prydz Bay, Antarctica, Atmos. Environ., 44, 1815-1821, 2010.
Yang, Y., Chen, H., and Wang, D.: Spatial and temporal distribution of gaseous elemental mercury in Chongqing, China, Environ. Monit. Assess., 156, 479-489, 2009.

Zhang, H., Lindberg, S. E., Marsik, F. J. and Keeler, G. J.: Mercury air/surface exchange kinetics of background soils of the Tahquamenon River Watershed in the Michigan Upper Penninsula, Water Air Soil Pollut., 126, 151-169, 2001.

Zheng, W., Feng, X. B., and Yan, H. Y.: Characteristics of total particulate mercury pollution in the atmosphere of a residential area in the city of Guiyang, PR China, Earth Environ., 35, 154-157, 2007. 